IBIMA Publishing

Journal of EU Research in Business

https://ibimapublishing.com/articles/JEURB/2019/479689/

Vol. 2019 (2019), Article ID 479689, 13 pages, ISSEN : 2165-9990

DOI : $10.5171 / 2019.479689$

Research Article

\title{
Social and Environmental Impacts Assessment in the Economy for the Common Good
}

\author{
Amparo Maset-Llaudes, David Cabedo, lluminada Fuertes and José \\ Miguel Tirado
}

Financial and Accounting Department, University of Jaume I, Castellón de la Plana, Spain

Correspondence should address to: Amparo Maset-Llaudes; maset@uji.es

Received date:11September 2017; Accepted date: 5February 2018; Published date:19 September 2019

Academic Editor: Paula Fernández González

Copyright @ 2019. Amparo Maset-Llaudes, David Cabedo, Iluminada Fuertes and José

Miguel Tirado. Distributed under Creative Commons CC-BY 4.0

\begin{abstract}
Traditional corporations handle their decision-making process according to a goal consisting in the generation of economic value, that is to say, the maximisation of the company value for the shareholders, maximisation of the economic added value, maximisation of profit, and so forth. Nevertheless, in recent years, a set of organisations that do not prioritise the creation of economic value have appeared, although they are not non-profits. Indeed, they pursue the generation of economic value, but at a level that guarantees their long-term viability. At the same time, their main objectives are not linked to this economic value, but are linked to the generation of positive social value or to the reduction of negative environmental impact. These "new" organisations, commonly referred to as hybrid organisations, need a tool to assess the social and environmental impacts they are generating, in order to guide their decisions concerning the goals they have set in these fields. In contrast to the accounting area, there is no generally accepted method to quantify the social or environmental impacts of a project, an activity or an organisation. Therefore, deeper research is required in this line. In th is paper, we analyse the items that the matrix of the Common Good Balance Sheet (MCGBS) requires for its calculation, and classify them according to their relevance for assessing social and environmental impacts. This allows us to evaluate whether these items (and, ultimately, the MCGBS) can be used as a means to quantify the social or environmental impacts generated by an organisation.
\end{abstract}

Keywords: Social Impacts, Environmental Impacts, Economy for the Common Good, Impacts Assessment

Cite this Article as: Amparo Maset-Llaudes, David Cabedo, Iluminada Fuertes and José Miguel Tirado (2019)," Social and Environmental Impacts Assessment in the Economy for the Common Good" Journal of EU Research in Business, Vol. 2019 (2019), Article ID 479689, DOI: 10.5171/2019.479689 


\section{Introduction}

Firms, institutions, organisations and governments are showing a growing interest in the effects of their actions. Nowadays, however, everybody accepts that these effects go beyond the economic impacts and an evaluation of the social and environmental impacts is also required. Indeed, a large number of institutions have developed initiatives to assess the social impact of their actions, which is a proof of how important this issue is for organisations. The diversity of the approaches used by organisations nevertheless highlights the huge complexity involved in this kind of assessment.

An organisation's efficiency is usually measured through a range of specific indicators, related to its scope and mission. This specificity undermines comparability of the information and can diminish its usefulness in decision-making processes.

The aim of this paper is to study the information available to economic organisations and, through the common good balance sheet (CGBS), analyse its value as a means to assess the social and environmental impact of their activities. To this end, we analyse the items used by the common good matrix (CGM) to elaborate the CGBS and then rank these items according to their usefulness to measure the social and environmental impacts. By so doing, we can determine to what extent these items (and, ultimately, the common good balance sheet - CGBS) can be useful as a means to assess the social and environmental impacts generated by the organisation.

We have structured our paper in the following way: after the introduction section, the social and environmental impacts and their assessment are defined in the second section. In the third, we show the main features of the balance sheet of the economy for the common good. Subsequently (in sections 4 to 6), we classify the indexes depending on the information they provide about social, environmental or mixed impacts. The last section summarises the main conclusions of the paper, shows its limitations and proposes future research lines.

\section{Social and Environmental Impacts}

Over the last few years, a growing interest has been observed in the assessment of social and environmental impacts generated by both governmental organisations and private firms. It is assumed that these impacts go beyond the accounting results to cover wide areas with a large number of stakeholders involved. One definition of social impact is that provided by Eccleston (2011:172), who claims that it is linked to the effects on the human population of any private or public action that modifies the way people live, work, act, relate and organise in order to satisfy their necessities and help them in acting as members of society. These effects also include cultural impacts that imply changes in the rules, values and beliefs that guide and streamline their knowledge of themselves and of their community.

The methods currently used to assess social impacts are still in an early stage of development. Ebrahim and Ragan (2010) classify the main methods of assessment of social impacts in terms of the different approaches employed. According to these authors, we can distinguish between methods that estimate the expected return, experimental methods, logical methods, strategic approaches, participative methods, relation-based methods and experimental approaches. They also say that those responsible for organisations are facing increasing pressure to demonstrate the impact of their activities on society. This pressure has been exacerbated by the specific budgetary requirements for organisations to make the impacts of their actions public in order to attract new funding (Lyon et al 2010, Chapman et al 2010). In this regard, in the Social Economy Report (2008) and the proposal for a "Regulation of the European Parliament and of the Council on the European Social Entrepreneurship Fund", the European Commission recommends the need for organisations to develop instruments to measure and compare the impact of their investments. In this sense, Diaz et al (2012) state that social impact assessment will be 
a key element, both in the search for the improvement of social and economic efficiency and in providing different stakeholders with adequate mechanisms of evaluation of the fulfilment of the organisation's social objectives. This need has also directly influenced the rating agencies of non-profit entities in the United States, which in recent years have renewed the rating parameters based purely on financial indicators, tending towards the development of social indicators (Charity Navigator et al 2009).

The interest in sustainable growth in recent years has not only led to concern about the social impacts of the organisations' actions, but has also increased the amount of attention paid to environmental impacts. This interest was boosted in 1987 with the publication of the Brundtland Report, where the concept of sustainable development was introduced for the first time, taking into account its three aspects: economic, social and environmental. Sustainable development has since been fostered by successive reports published by the UN World Commission on Environment and Development.

The increasing concern for sustainable growth over the last few years has led to a growing interest in not only social but also environmental impacts. The first studies on the impacts that human actions leave on the environment (Environmental Impact Assessment, EIA) can be dated back to the USA in the late 1960s and introduced the first controls and instruments to evaluate the repercussion of human actions. One definition of impact assessment can be found in Abaza et al (2004), who claim that this assessment refers to the evaluation of the repercussion of a higher project or action that affects the natural and artificial environment. The definition that the International Association for Impact Assessment (IAIA) provides for EIA relates it to the process (undertaken before relevant decision-making and commitments) of identification, forecasting, evaluation and mitigation of the biological, social and other effects that stem from development proposals (see Vanclay, 2015). Eccleston (2011) claims that EIA can be defined as the accumulated results of a project or activity that generate changes in the environment or ecosystem over time and space.

As for social impacts, nowadays there is no method that can be used by itself for environmental impact assessment, given the variety of firms and the different kinds of actions that can generate an impact. The different methodologies for environmental impact assessment can be classified, among others, into matrix methods (such as the Leopold method), Odum's optimum pathway matrix, modelling methods or simulation techniques, and indicator methods. This last group evaluates environmental impacts through previously established indicators, to which a weighted value is assigned and a final score is set for each of them. Therefore, the MCGBS can be classified within this group of methods.

The two most widely used methods of impact assessment are Social Audit Accounting (SAA) and Social Return on Investment (SROI), the latter has received more attention in the literature (Emerson, 2003; Gair, 2002; Arvidson et al, 2009; Nicholls et al, 2012; Lingane and Olson, 2004). SROI attempts to express the social value generated by the activities carried out by entities in monetary values, based on cost-benefit principles (Flockhard, 2005; Arvidson et al, 2010; Millar and Hall, 2012). Unlike the CGBS method, it adapts itself to the project to be analysed and the interest groups will vary depending on the project. However, carrying out the CGBS is aimed at all the stakeholders that make up society. Other differences between the two methods are that the CGBS can be adapted to apply to organisations, enterprises and municipalities, and SROI is an instrument that applies to particular projects. Accordingly, an organisation can apply the CGBS to the set of all its activities and the SROI to each of them separately, so the first method will give us an overview of the performance of the entity and the SROI will offer a partial view of each of these actions.

Derived from the above and from the temporal point of view, the CGBS covers the activity of the company throughout the same period in which, in accordance with 
Spanish legislation, companies are required to draw up their accounting and financial reports, that is to say, an accounting year, which usually coincides with the calendar year. The SROI may cover different periods other than a year because the projects analysed by this method can have different durations (greater or less than a year). Thus, if some kind of comparative study were to be carried out between the two methods, it would be advisable for the projects analysed by SROI to also have a duration equal to one calendar year.

On the other hand, the SAA method uses quantitative and qualitative analyses, as well as ratio analysis to measure the activities carried out by the enterprise. It is an internal organisational system implemented by the company and moderated by an independent external evaluator. In contrast, the CGBS does not need interventions from outside the firm to carry out its evaluations. Another point on which the two methodologies coincide is that they are both standardised models, and so comparisons can be made between companies that adopt these methods. This implies that it is possible to show an image of the joint situation of the sector to which these companies belong. Both methods can also be applied to all kinds of organisations (profit and non-profit) and to municipalities. Furthermore, the SAA method, like the SROI, is carried out through several successive stages, although the CGBS does not need the calculations of the indicators to be ordered sequentially.

The SAA system could be placed within the orbit of the analyses based on the Triple Bottom Line as it incorporates the study of commercial and financial, social and community, and environmental and society areas. This is similar to the CGBS, which incorporates indicators related to the social and environmental field into the CGM and the economic-financial field being covered by the annual accounts of the company.

When it comes to choosing the most appropriate method, it is necessary to determine in advance whether the study will be directed towards the funders or investors or whether it is focusing on stakeholders' accountability. On the other hand, and given that both the SAA and the CGBS are methodologies that include environmental aspects, according to Gibbons and Dey (2011), the principles and application of SROI should also meet the demands of the Triple Bottom Line, including social and environmental as well as economic aspects, in order to provide verifiable and complete information about the company's activity.

\section{The Common Good Balance Sheet}

As regards changes in the economic model, one of the most comprehensive and innovative approaches is the Economy for the Common Good, which comprises instruments like the Common Good Balance Sheet and Matrix, which many firms have adopted in recent years. The CGBS is based on a series of indicators that make up the CGM. This is a flexible instrument that has been continuously evolving to adapt itself to the social and environmental situation since it was created five years ago. As a result, several versions have been released to date. Table 1 shows version 4.1 of this matrix: 
Table 1: Common Good Balance Sheet (Matrix 4.1)

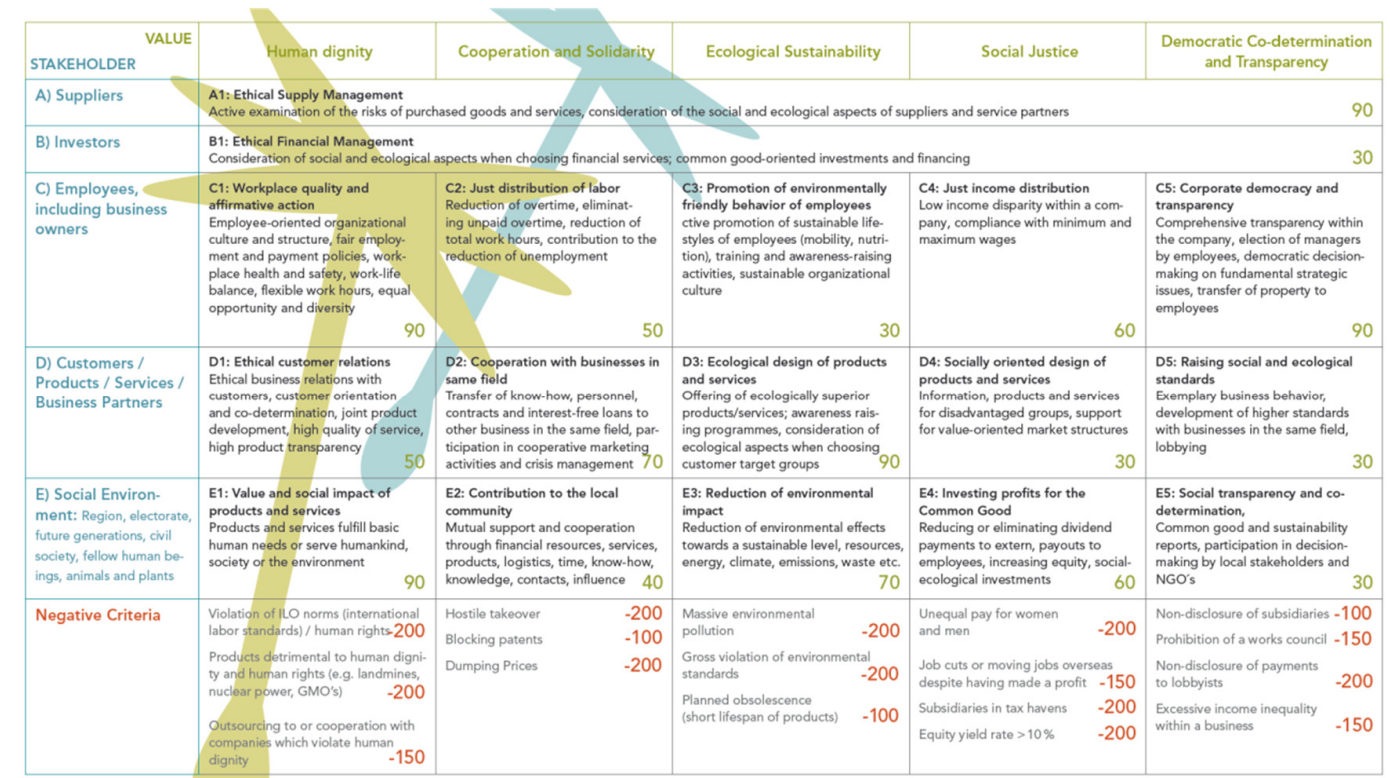

Source: https://www.ecogood.org/en/common-good-balance-sheet/common-good-matrix/

Although the CGBS encompasses topics beyond those related to the environment, on analysing the social effects of the firms' actions, one could consider them as a kind of EIA, since it involves an evaluation of the activities that negatively affect the environment. Therefore, this paper focuses on classifying the items in the MCGBS (Table 1) into those related to the social area, those regarding the environmental field, and those that could belong to both areas and hence cannot be separated.

\section{Common Good Balance Sheet: Social Impacts}

In practice, the measurement of social impact is often confined to just a series of individual indicators. As a result, the information provided does not reflect a global vision and is segmented and biased, as it fails to offer a common view of the different facets of social impact (Díaz et al, 2012). Therefore, it is necessary to analyse and determine which methods for measuring social impact are more suitable for different types of organisations, with the aim of reducing the gap that exists between the information that is currently disseminated by organisations about impact assessment and the different existing models.

Taking the CGM as an instrument for measuring impacts (see Table 1), and ignoring the way enterprises that adhere to this movement record the score when they attempt to implement the CGBS, in the following sections, the impacts will be classified in the three groups referred to above.

The indicators of the CGM which may be directly related to the social area are:

\section{Employees, Including Business Owners}

\section{C1 Workplace quality and affirmative action}

C1.1 Employee-oriented organisational culture and structure

C1.2 Fair employment and payment policy

C1.3 Occupational safety and workplace health promotion including work-life balance / flexible work hours 


\section{C1.4 Affirmative action and diversity}

The need to achieve equality between all the people in the company and their full development as individuals is valued with special attention given to their health. Hence, it is important to avoid the imbalances between different groups such as people with disabilities, migrants, the long-term unemployed, minorities, and so on, and to promote gender equality.

\section{C4 Just income distribution}

C4.1 Income divergence in the company

C4.2 Minimum income

C4.3 Transparency and institutionalisation

The wage differences between workers are increasing and this difference, according to Social Medicine, engenders sick societies, which suffer greater inequality and higher crime rates. To solve this issue, it would be advisable to establish a fairer distribution of the workers' income from the performance point of view.

\section{Customers/ Products/ Services/ Partners}

\section{D1 Ethical Customer Relations}

D1.1Total extent of ethical customer relations measures (ethical marketing + sales)

D1.2 Product transparency, fair pricing and ethical selection of customers

D1.3 Extent of customer co-determination / joint product development / market research

D1.4 Extent of customer co-determination / joint product development / market research

In today's society, there is a danger that the customer will be seen as a means to obtain an end, that is, a way to increase profits by using advertising to encourage compulsive and unsustainable purchasing, when purchases should be thoughtful and rational.

D2 Cooperation with businesses in same sector
D2.1 Disclosure of information and passing on of technology

D2.2 Passing on of personnel, contracts and financial resources; cooperative market participation

D2.3 Cooperative marketing

The aim is to encourage cooperation rather than competition among companies, because this is considered to be the way to achieve a higher return.

D4 Socially oriented design of products and services

D4.1 Facilitation of access to information / products / services for disadvantaged customer groups

D4.2 Structures worthy of promotion are supported by sales policies

The level of social responsibility is evaluated from the customers' point of view. This is achieved by considering whether there are facilities that make access by disadvantaged consumers easier, since these have to be a reference for the production of goods and services.

\section{E Social Environment: Region, Electorate, Future Generations, Civil Society, Fellow Humans, Animals, Plants}

E2 Contribution to the local
community
E2.1 Achievements
E2.2 Effects
E2.3 Intensity

It is considered that the company can act as non-monetary contributor to the community, in a similar way to how an individual could, by trying to cover some of its deficits. This could be done through donations, foundations, etc.

\section{N Negative Criteria}

\section{N1 Violation of human dignity}

N1.1 Violation of ILO norms/human rights 
N1.2 Products detrimental to human dignity and human rights

N1.3 Outsourcing to or cooperating with companies which violate human dignity

Companies must ensure compliance with current regulations on human rights and standards issued by the International Labour Organisation.

\section{N2 Non-cooperative behaviour}

\section{N2.1 Hostile takeover}

\section{N2.2 Blocking patents}

\section{N2.3 Dumping prices}

In relation to mergers and the acquisition of companies, this should not involve a hostile takeover, and individuals belonging to the company should be able to intervene in the acquisition agreements. With regard to the actions of companies concerning the innovation of products or processes, patents will not be used to hinder other companies from developing innovations that can modify the business status quo in the markets (defensive patenting). The application of dumping is also considered a negative strategy.

\section{N4 Socially unjust behaviour}

\section{N4.1 Unequal pay for women and men}

N4.2 Job cuts or moving jobs overseas despite having made a profit

\section{N4.3 Subsidiaries in tax havens}

\section{N4.4 Equity yield rate $>10 \%$}

There should be no gender inequality with regard to wages, and so if a company has been convicted in relation to this matter, or reliable proof of such inequality can be demonstrated, the company will receive a negative score. Dismissal of workers when the company is making a profit, business transfers and closures, and the existence of any kind of relationship with tax havens will also be considered negatively (due to the possibility of tax evasion). Further examination will also need to analyse the firm's situation as regards capital gains.

\section{Common Good Balance Sheet: Environmental Impacts}

Environmental impact is the effect of any human activity on the natural landscape, climate, and so forth. Environmental impacts produced by business activity can have serious consequences (especially if we are talking about industrial companies) on the health of individuals (both people linked with the company and those who do not have a direct relationship with the enterprise), as well as on the quality of the air, on the recycling of waste, on pollution, and so on. In short, we are talking about effects on the quality of life.

The CGM indicators that are seen to be related to the environmental area are:

\section{A Suppliers}

\section{A1 Ethical Supply Management}

A1.1 Regional, ecological and social aspects / superior alternatives are considered A1.2 Active examination of impact of purchased products / services and processes for ensuring goal achievement and extent and form of procedure for verification

A1.3Active examination of impact of purchased products / services and processes for ensuring goal achievement and extent and form of procedure for verification

According to this indicator, companies should take into account the ethical conditions of suppliers and products, for example by assessing precarious working conditions, fair trade, tourism services, cleaning services, etc.

\section{B. Investors}

B1 Ethical Financial Management

B1.1 Institutionalisation 
B1.2 Ethical / sustainable quality of financial service providers

B1.3 Investments oriented to the common good

B1.4 Corporate financing oriented to the common good

Businesses should be made aware of the effects of the financial sector (especially potentially destructive effects). However, this awareness is a little weak. In consequence, the levels of both the demand and the supply of ethical-ecological or sustainable financial products are not very high.

\section{Employees, Including Business Partner}

\section{C2 Just distribution of labour}

\section{C2.1 Reduction of normal working time}

C2.2 Increase in proportion of part-time work models and use of temporary employment (with adequate pay)

C2.3 Conscious approach towards (life-) working time

The distribution of work in today's society is highly unequal: there are individuals working a large number of hours (overtime), while others do not do so at all. From the ecological point of view, this is highly inefficient and it would be desirable for society to share working hours out more equitably.

C3 Promotion of environmentally friendly behaviour of employees

\section{C3.1 Nutrition during working time}

\section{C3.2 Mobility to workplace}

C3.3 Organisational culture, awareness raising and in-house processes

By complying with the conditions of this item, the aim is to raise awareness of the need to achieve ecologically sustainable development. To this end, it is considered necessary to have an awareness based on fundamental rights such as food or mobility, as well as working conditions which guarantee truly appropriate behaviour by individuals.

\section{D.Customers/Products/Services/Partne} rs

D3 Ecological design of products and services

D3.1 In ecological comparison to $\mathrm{P} / \mathrm{S}$ of competitors or alternatives, products / services have equal utility

D3.2 Sufficiency (see excursus below): active design for ecological utilisation and sufficient consumption

D3.3 Communication: active communication of ecological aspects to customers

It is widely accepted that the production of goods and services involves a consumption of resources that exceeds the reserves that are available. The aim is to promote efficiency in the use of productive factors, beyond the actions followed in this regard to date, which are sometimes insufficient (for example, the use of renewable raw materials). For an action in this respect with effective effects on real overconsumption, it would be necessary to make clients aware of their patterns of consumption, or even reduce it as much as possible (food consumption).

\section{E Social Environment: Region, Electorate, Future Generations, Civil Society, Fellow Humans, Animals, Plants}

\section{E3 Reduction of environmental impact}

\section{E3.1 Absolute impact}

E3.2 Relative impact: In sectorial comparison, as far as the state of the art and legal requirements are concerned, the company lies ...

\section{E3.3 Management and strategy}

Given the extent of the influence on the environment at both national and global 
levels, it is necessary for companies and sectors to reduce it. This could be reflected, for example, in water consumption, recycling, reuse of materials, reduction of emissions, etc.

\section{N Negative Criteria}

\section{N3 Environmental degradation}

\section{N3.1 Massive environmental pollution}

N3.2 Gross violation of environmental standards

N3.3 Planned obsolescence (short lifetime of products)

The objective in this case is to minimise the effects of the destruction of natural areas. An enterprise will be given a negative score if it can be demonstrated that the firm has been sentenced in relation to such aspects or even if it causes environmental burdens.

\section{The Common Good Balance Sheet: Mixed Impacts}

The relationship between social and environmental impacts is now fully accepted. For example, research by Rettenmaier and Hienz (2014) has revealed a positive trade-off between socio-economic and environmental impacts. Sinha Babu and Datta (2015) claim that both areas are intricately connected and, moreover, that environmental and social factors are correlated when analysing their effects on the well-being of individuals. Thus, the effects of the programmes and actions of companies and organisations affect both individuals and the environment and, in most cases, the effects are deeply associated with each other. As indicated by RHEAS (Spanish-speaking Network for Environmental and Social Assessment) "the social component has become one of the fundamental aspects of environmental assessment". In fact, this network states that "in Legislative Royal Decree 1/2008, Spanish national law specifies that the EIA will identify, describe and evaluate the direct and indirect effects of a project on human beings, cultural heritage and their interaction with the environment".

The CGM indicators that are considered as being possibly related to both the social area and the environmental field are:

\section{D.Customers/Products/Services/Partne rs}

D5 Raising social and ecological standards

D5.1 Cooperation with competitors and partners of the value chain

D5.2 Active contribution to raising legislative standards

D5.3 Range, content-related scope and depth

Companies should increase cooperation and the dissemination of information on social and environmental standards (political processes, lobbying activities, quality, etc.).

\section{E Social Environment: Region, Electorate, Future Generations, Civil Society, Fellow Humans, Animals, Plants}

E1 Products / services meet a basic need or serve the development of human beings / the community / the earth and generate positive use

E1.1 Products / services meet a basic need or serve the development of human beings / the community / the earth and generate positive use

E1.2 Ecological and social comparison of products / services with alternatives of similar final benefit

Individuals consume goods and services because they are useful to them, but this cannot be the sole objective of consumers. The effects deriving from the actual consumption of goods and services and whether this consumption is compatible with the environment and society should also be taken into account. 
E5 Societal transparency and codetermination

\section{E5.1 Scope of CG Report}

E5.2 Type of co-determination and documentation

E5.3 Scope of co-determination and stakeholder integration

The company must provide all the stakeholders with information about its actions; in other words, it must be transparent about its participation in other companies, and how its actions affect both individuals and the environment (level of pollution, recycling, and so forth).

\section{N5 Undemocratic behaviour}

N5.1 Non-disclosure of subsidiaries

\section{N5.2 Prohibition of a works council}

N5.3 Non-disclosure of payments to
lobbyists

N5.4 Excessive income inequality within a business

As was the case previously with the equivalent positive indicator (C5), this item is also considered to be of a mixed nature. Any action that involves in some way a decrease in transparency will be considered an increase in the negative aspects of the company. These actions will be related to aspects discussed above, such as actions which may result in tax evasion, actions which have effects on the environment, and actions with political implications resulting from relations with certain political parties or lobby groups.

A summary of the indicators of the CGM classification, in terms of the type of impact, is shown in Table 2:

Table 2: Impact Indicators Classification

\begin{tabular}{|c|c|c|c|c|}
\hline & & $\begin{array}{c}\text { Social } \\
\text { Impact } \\
\text { Indicators }\end{array}$ & $\begin{array}{l}\text { Environmental } \\
\text { Impact } \\
\text { Indicators }\end{array}$ & $\begin{array}{c}\text { Mixed } \\
\text { Impact } \\
\text { Indicators }\end{array}$ \\
\hline A. SUPPLIERS & $\mathrm{A} 1$ & & $\mathbf{X}$ & \\
\hline B. INVESTORS & B1 & & $\mathbf{X}$ & \\
\hline \multirow{5}{*}{$\begin{array}{l}\text { C. EMPLOYEES, INCLUDING } \\
\text { BUSINESS PARTNER }\end{array}$} & $\mathrm{C} 1$ & $\mathbf{X}$ & & \\
\hline & $\mathrm{C} 2$ & & $\mathbf{X}$ & \\
\hline & $\mathrm{C} 3$ & & $\mathbf{X}$ & \\
\hline & $\mathrm{C} 4$ & $\mathbf{x}$ & & \\
\hline & $\mathrm{C} 5$ & & & $\mathbf{X}$ \\
\hline \multirow{5}{*}{$\begin{array}{c}\text { D. } \\
\text { CUSTOMERS/PRODUCTS/SERVI } \\
\text { CES/PARTNERS }\end{array}$} & D1 & $\mathbf{X}$ & & \\
\hline & D2 & $\mathbf{x}$ & & \\
\hline & D3 & & $\mathbf{X}$ & \\
\hline & $\mathrm{D} 4$ & $\mathbf{X}$ & & \\
\hline & D5 & & & $\mathbf{X}$ \\
\hline \multirow{3}{*}{$\begin{array}{c}\text { E. SOCIAL ENVIRONMENT: } \\
\text { REGION, ELECTORATE, FUTURE } \\
\text { GENERATIONS, CIVIL SOCIETY, } \\
\text { FELLOW HUMANS, ANIMALS, } \\
\text { PLANTS }\end{array}$} & E1 & & & $\mathbf{X}$ \\
\hline & E2 & $\mathbf{x}$ & & \\
\hline & E3 & & $\mathbf{x}$ & \\
\hline
\end{tabular}




\begin{tabular}{|l|c|c|c|c|}
\hline \multirow{4}{*}{ NEGATIVE ASPECTS } & E4 & $\mathbf{X}$ & & \\
\cline { 2 - 6 } & E5 & & & $\mathbf{X}$ \\
\hline & N1 & $\mathbf{X}$ & & \\
\cline { 2 - 6 } & N2 & $\mathbf{X}$ & & \\
\cline { 2 - 6 } & N3 & & $\mathbf{X}$ & $\mathbf{X}$ \\
\hline & N4 & X & & \\
\cline { 2 - 6 } & N5 & & & \\
\hline
\end{tabular}

Source: Author's own elaboration

\section{Conclusions}

In recent years, companies are detecting changes that are leading them to accept that their activity has impacts that have not only economic, but also social and environmental effects. However, there is no system for collecting and measuring information with a level of consensus analogous to that of economics or accounting and which allows us to consider the value of the social or environmental impact of a particular project or organisation, and which favours the comparability of information for decisionmaking. It should be emphasised that considerable progress has been made in recent years in the measurement of impacts other than economic ones, that is, the social and environmental impacts of the projects undertaken by organisations. At this point, the contributions made by the CGBS methodology are especially significant.

According to this work, and in the light of the results obtained and summarised in the previous table, it can be stated that approximately half of the indicators and/or sub-indicators in the CGM correspond to the social area (more specifically slightly more than 45\%), and the environmental aspect being considered in only one third of the indicators and sub-indicators of this matrix. Thus, aspects directly related to the quality of life of individuals and their improvements are widely represented in this tool, but the effects on the environment and surroundings are less abundant. This claim does not necessarily imply that the differences in the number of second level indexes indicate differences in quality, in the items or in the instrument itself, which is backed by the results obtained and the high degree of satisfaction with its use in many companies. For these reasons, it cannot be said that the environmental area is represented only precariously in the CGM.

On the other hand, it should be noted that this is a preliminary analysis, and it would be necessary to delve into this subject with a deeper, broader and more exhaustive study. One of the possible derivations of this work would be to carry out analyses at the individual level for each organisation, and another (which is now under way) consisting in classifying the impacts according to different criteria, some of which have been pointed out previously. For example, consideration could be given to the classification of the different indicators studied according to the different points of view in the environmental area, such as the nature of the impact, the cause-effect relationship, its extension, persistence, recovery, manifestation or its interrelation with other impacts. This will allow us to obtain concepts, principles, methodologies and practices that can become balanced and reliable instruments for a better social and environmental assessment. In this respect, it should be noted that this approach (and therefore the metrics involved) has recently received a boost from the regional government through Order 2/2017, dated 21 February, of the Conselleria de Economía Sostenible, Sectores Productivos, Comercio y Trabajo of the Generalitat Valenciana. This example shows the growing interest of public administrations in the promotion of policies aimed at creating social and environmental value. 


\section{Acknowledgment}

This research was supported by Generalitat Valenciana Promotion Plan (Order of May 23rd 2017 of Council of Sustainable Economy)

\section{References}

1. Abaza, H., Bisset, R., and Sadler, B. (2004), 'Environmental impact assessment and strategic,' [Online], [Retrieved December 2017, http://unep.ch/etu/publications/text_ONU _br.pdf

2. Chapman, T., Robinson, F., Brown, J., Crow, R., Bell, V. and Bailey, E. (2010), 'What makes third sector organisations tick? Interactions of foresight, enterprise, capability and impact,' Northern Rock Foundation, Newcastle.

3. Arvidson, M., Lyon, F., McKay, S. and Moro, D. (2010), 'The ambitions and challenges of SROI', Working Paper 40, Third Sector Research Centre, University of Birmingham.

4. Charity Navigator (2017), Website: http://www.charitynavigator.org (last accessed 2 Setember 2017).

5. CESE, Consejo Económico Social y Europeo (2008), Informe sobre la Economía Social. Comisión Europea.

6. Díaz, M., Marcuello, C. and Marcuello, Ch. (2012), Empresas sociales y evaluación del impacto social, CIRIEC 75, 179-198.

7. Ebrahim, A. and Rangan V. K. (2010), 'The Limits of Nonprofit Impact: A Contingency Framework for Measuring Social Performance,' Working Paper 10-53. Harvard Business School.

8. Eccleston, C. H. (2011), 'Environmental impact assessment: A guide to best professional practices,' CRC Press.

9. Elkington, J. (1997), 'Cannibals with Forks: The Triple Bottom Line of $21^{\text {st }}$ Century,' New Society Publishers.

10. Emerson, J. (2003), 'The blended value proposition: integrating social and financial returns,' Californian Management Review 45 (4): 35-45.

11. Gair, C. (2002), 'A Report From the Good Ship SROI,' (On line: REDF, http://www.redf.org/publications-

sroi.htm\#ship, (last accessed 25 Setember 2017).
12. Gibbon, J. and Dey, C. (2011), 'Developments in Social Impact Measurement in the Third Sector: Scaling Up or Dumbing Down?,' Social and Environmental Accountability Journal 31 (1): 63-72.

13. Lingane, A. and Olsen, S. (2004), 'Guidelines for social return on investment,' California Management Review 46 (3): 11635.

14. Lyon, F., Arvidson, M., Etherington, D., and Vickers, I. (2010), 'Social impact measurement (SIM) experiences and future directions for third sector organisations in the East of England,' report for the East of England Development Agency, at www.theguild.co.uk (last accessed 27 Setember 2017).

15. Millar, R. and Hall, K. (2012), 'Social Return on Investment (SROI) and Performance Measurement: The opportunities and barriers for social enterprises in health and social care,' Public Management Review 1-19.

16. Nicholls, J., Lawlor, E., Neitzert, E. and Goodspeed, T. (2012), 'A guide to social return on investment,' Lothian: The SROI Network.

17. Order 2/2017, dated 21 February. Conselleria de Economía Sostenible, Sectores Productivos, Comercio y Trabajo. Generalitat Valenciana (last accessed 2 Setember 2017).

18. Our Common Future: Brundtland Report. 20 March 1987. UN.

19. Rettenmaier, N. and Hienz, G. (2014), 'Linkages Between Socio-Economic and Environmental Impacts of Bioenergy,' Socio-Economic Impacts of Bioenergy Production (59-80).

20. Sinha Babu, S. and Datta, S.K. (2015), 'Revisiting the link between socioeconomic development and environmental status indicators-focus on panel data,' Environment, Development and Sustainability, June 2015, 17 (3) 567586 https://doi.org/10.1007/s10668014-9561-6

21. Vanclay, F. (2015), 'Social Impact Assessment: Guidance for Assessing and Managing the Social Impacts of Projects,' IAIA. 


\section{Footnotes}

Triple Bottom Line: The term Triple Bottom Line was coined by Elkington in 1997, in the book "Cannibals with Forks...". The Triple Bottom Line measures the company's degree of social responsibility, the economic value and the environmental impact of an enterprise. So, companies should include assessments about social and environmental aspects of their activities within their accounts so as to be able to measure the total cost of doing business.

CGBS: Companies assess the impacts of their actions in the areas listed in Table 1 (more in five sub-areas that reflect the possible negative impacts) by awarding scores drawn from scales previously established. The scores reflect the level of compliance with the 22 indicators listed in the table above, (the items from A1 to E5, the negative ones, and the respective subindicators). The aim is to enable enterprises to assess their level of compliance, obtaining a final score. However, this is not the main objective of the evaluation of an organization from the point of view of the Economy of the Common Good. The calculation of the result of this tool is indissolubly linked to the report that will reflect the deficiencies, the objectives to be achieved in the future, and the way forward for it. 